\title{
The Importance of Continuity of Care in Children with Asthma
}

\author{
Shu-Tzu Huang ${ }^{1}$, Yee-Yung $\mathbf{N g}^{3}$ and Shiao-Chi $\mathbf{W u}^{* 1}$ \\ ${ }^{1}$ Institute of Health and Welfare Policy, School of Medicine, National Yang Ming University, Taiwan \\ ${ }^{2}$ Taipei Veterans General Hospital, Taiwan (ROC)
}

*Corresponding author: Wu SC, Institute of Health and Welfare Policy, School of Medicine, National Yang Ming University, Taiwan, Tel: 886-2-2826-7052; Fax: 886-2-2820-4735; E-mail: scwu@ym.edu.tw

Rec date: March 12, 2016 Acc date: May 18, 2016 Pub date: May 23, 2016

Copyright: (C) 2016 Huang ST, et al. This is an open-access article distributed under the terms of the Creative Commons Attribution License, which permits unrestricted use, distribution, and reproduction in any medium, provided the original author and source are credited.

\section{Commentry:}

Continuity of care (COC) means the condition of "care over time by a single individual or team of health professionals," [1] which is a cornerstone of primary care. With continuous care, patients tend to have higher quality of care, i.e., greater satisfaction, decreased emergency department (ED) visits and hospitalizations, and improved receipt of preventive services [2]. Physicians who have long-term relationships with their patients may better manage the chronic diseases because they are more familiar with their patients' medical history and can effectively communicate with their patients. This was particularly found in patients with asthma. Love et al. [3] found a positive correlation between COC and patient perceptions of physician-patient communication.

Asthma is the most common non-communicable disease among children, whose airway inflammation is still present during clinical remission of atopic asthma [4]. The continuous treatment with inhaled corticosteroids for children with asthma leads to effective control of asthma and ensure the safety of long-term treatment for asthma [5-7]. Therefore proper disease management can avoid asthma attack or ED visit. The report "Global strategy for asthma management and prevention" from Global Initiative for Asthma emphasizes that effective asthma management requires a partnership between the patient (or the parent/carer) and the healthcare providers [8]. Physician-patient partnership can be developed through long-term relationship, in other words, COC. Numerous studies have revealed that higher COC can reduce asthma ED utilization in patients with asthma [9-11]. Our research, which was under the national health insurance system in Taiwan, supported the finding as well. The groups with medium and low COC had $21 \%$ (odds ratio [OR], 1.21; 95\% CI, 1.06-1.39) and 38\% (OR, 1.38; 95\% CI, 1.21-1.58) higher asthmarelated ED utilization, respectively, than the group with high COC [12].

Besides, Cabana et al. [13] found that if patients with asthma who discharged from ED presented for outpatient follow-up, they had an increased likelihood for repeat ED asthma visits. For these patients, continuity of care should strongly be enhanced. Therefore, improving the COC becomes important for the patients with asthma and healthcare providers. The healthcare providers could actively make the follow-up visit appointment and remind the patient (or the parent/ carer) in advance. Government could initiate pay-for-performance program of asthma to motivate physicians and patients to improve the $\mathrm{COC}$ and self-care ability for reducing the ED visit and hospitalization.

\section{Acknowledgements}

The authors would like to thank the Ministry of Science and Technology (project number: 103-2410-H-010-011-MY2) in Taiwan for support.

\section{References}

1. Donaldson MS, Yordy KD, Lohr KN, Vanselow NA (1996) Primary Care: America's Health in a New Era. National Academy Press, Washington DC.

2. Cabana MD, Jee SH (2004) Does continuity of care improves patient outcomes? J Fam Pract 53: 974-980.

3. Love MM, Mainous Agi, Talbert JC, Hager GL (2000) Continuity of care and the physician-patient relationship. J Fam Pract 49: 997-998.

4. Van Den Toorn LM, Overbeek SE, De Jongste JC, Leman K, Hoogsteden $\mathrm{HC}$, et al. (2001) Airway inflammation is present during clinical remission of atopic asthma. Am J Respir Crit Care Med 16: 2107-2113.

5. Anonymous (2000) Long-term effects of budesonide or nedocromil in children with asthma. N Engl J Med 343: 1054-1063.

6. Brand PL (2001) Inhaled corticosteroids reduce growth. Or do they? Eur Respir J 17: 287-294.

7. Schlienger RG, Jick SS, Meier CR (2004) Inhaled corticosteroids and the risk of fractures in children and adolescents. Pediatrics 114: 469-473.

8. From the Global Strategy for Asthma Management and Prevention, Global Initiative for Asthma (GINA) 2015.

9. Cree M, Bell NR, Johnson D, Carriere KC (2006) Increased continuity of care associated with decreased hospital care and emergency department visits for patients with asthma. Dis Manag 9: 63-71.

10. Cyr MC, Martens AC, Berbiche D, Perreault S, Blais L (2006) Continuity of care in the ambulatory treatment of adolescents with asthma. J Adolesc Health 39: 926.e11-926.e17.

11. Hong JS, Kang HC, Kim J (2010) Continuity of care for elderly patients with diabetes mellitus, hypertension, asthma, and chronic obstructive pulmonary disease in Korea. J Korean Med Sci 25: 1259-1271.

12. Huang ST, Wu SC, Hung YN, Lin IP (2016) Effects of continuity of care on emergency department utilization in children with asthma. Am J Manag Care 22: e31-e37.

13. Cabana MD, Bruckman D, Bratton SL, Kemper AR, Clark NM (2003) Association between outpatient follow-up and pediatric emergency department asthma visits. J Asthma 40: 741-749.

Citation: Shu-Tzu Huang, Yee-Yung Ng and Shiao-Chi Wu (2016) The Importance of Continuity of Care in Children with Asthma.Gen Med (Los Angeles) 4: 243. doi:10.4172/2327-5146.1000243 